\title{
Introduction
}

\section{Diagnostic Procedures in Psychogeriatric Medicine}

Interest in the health and diseases of elderly people has been growing in most parts of the world during the last few decades. One reason is that knowledge of normal aging and of the manifestations of disease in the higher age groups has been incomplete compared to the corresponding knowledge regarding other periods of human life. Another reason is the increasing absolute and relative number of elderly not only in the developed, but also importantly in the developing world. It is estimated, for example, that the increase of the population aged 80 and over from 1980 to 2020 will amount to $108 \%$ in the developed world compared to $377 \%$ in the developing world (U.N. Department of International Economic and Social Affairs, 1985).

Psychogeriatric medicine is a young discipline in Sweden as well as in other parts of the world; for review see Bucht and Steen (1990). Prior to the establishment of the discipline, patients with psychogeriatric diseases have been treated in a variety of ways during the last thousand years or more. In current times, especially the last decade, paralleling the development of basic research in mental disorders of the elderly, there has been the extensive development of institutional care and fundamental care of mentally ill elderly patients.

The most important issue in the field of psychogeriatic medicine in Sweden, as well as in other parts of the world, is how to approach the problem of dementia in the elderly. One of the main research interests in Sweden is the etiology of Alzheimer's disease, which is still unknown. The hypothesis of genetic predisposition is one line of study, and chromosomal aberrations in patients with Alzheimer's disease have been shown (Nordensson, Adolfsson, Beckman, Bucht, \& Winblad, 1980; Bucht, Adolfsson, Beckman, Nordensson, \& Winblad, 1985). Another main research line is the possibility of a disturbed blood-brain barrier leading to an immunologic process which, in turn, leads to Alzheimer's disease (Alafuzoff, Adolfsson, Bucht, \& Winblad, 1983). Deficiencies in neumotransmittors in patients with Alzheimer's disease were early reported from our country. In addition, different Swedish groups have reported definite disturbances in the central cholinergic, noradrenergic and serotinergic system (for review see Hardy et al., 1985).

Clinical research in Sweden has focused also upon different diagnostic procedures. It has come to be accepted that all patients in whom a dementia syndrome is suspected are offered a detailed diagnostic examination to avoid overdiagnosis. 
In one study, patients with symptoms or signs of organic brain failure were examined with a wide test battery (Hedner, Gustafson, Steen, \& Steen, 1987). As many as $3 \%$ of the patients had treatable dementia and $8 \%$ had nondementia conditions.

Many of the psychogeriatricians in Sweden are members of the Intemational Psychogeriatric Association (IPA), a relatively young organization. Its achievements, however, are manifold: workshops; international congresses in Cairo, Umeâ, Chicago, Tokyo, and Rome; a scientific journal, International Psychogeriatrics; and member newsletters.

The workshops are designed to offer participants a chance to acquaint themselves with new developments in a specific area and to informally discuss them with colleagues and friends from all over the world during the lecture and poster sessions, during the plenary workshops, and informally outside the lecture hall. Earlier workshops have taken place in Cologne, Paris, Baden bei Wien, Lausanne, Budapest, and Modena. Thus, this workshop in Gothenburg was our seventh, organized by the Departments of Geriatric and Long-term Care Medicine, and Psychiatry and Neurochemistry of the Gothenburg University, and with honorary cosponsorship from the World Health Organization and the Nordic Federation for Gerontology.

The organizing committee chose Diagnostic Procedures in Psychogeriatric Medicine as the theme for this workshop, the sessions being devoted to clinical diagnosis of organic syndromes, biological markers, neuropsychological diagnosis, brain imaging, and postmortem diagnosis, respectively, each comprising keynote lectures, free communications and poster presentations. This theme was selected because there has been a tremendous development in new technology and knowledge relating to these topics. At the same time there is an urgent need to improve diagnostic efforts in research and clinical work to avoid underdiagnosis and overdiagnosis. The increasing absolute and relative number of elderly in most countries of the world also underscores the importance of the theme of this workshop.

We were happy to greet a great number of colleagues and friends from most parts of the world who chose to come to this workshop and take pleasure in presenting the eight keynote lectures from the workshop in one thematical issue of International Psychogeriatrics.

\section{REFERENCES}

Alafuzoff, I., Adolfsson, R., Bucht, G., \& Winblad, B. (1983). Albumin and immunglobulin in plasma and cerebrospinal fluid barrier function in patients with dementia of Alzheimer's type and multi-infarct dementia. Journal of the Neurological Sciences, $60,465-472$.

Bucht, G., Adolfsson, R., Beckman, G., Nordensson, I., \& Winblad, B. (1985). Genetic aspects on normal aging and dementia of Alzheimer's type (AD/SDAT). In C. G. Gottfries (Ed.), Normal aging, Alzheimer's disease and senile dementia. Aspects on etiology, pathogenesis, diagnosis and treatment (pp. 95-103). Brussels: Editions de l'Universitć de Bruxelles. 
Bucht, G., \& Steen, B. (1990). Development of psychogeriatric medicine in Sweden. International Psychogeriatrics, 2, 73-80.

Hardy, J., Adolfsson, R., Alafuzoff, I., Bucht, G., Marcusson, J., Nyberg, P., Perdahl, E., Wester, P., \& Winblad, B. (1985). Transmitter deficits in Alzheimer's disease. Neurochemistry International, 7, 545-563.

Hedner, K., Gustafson, L., Steen, G., \& Steen, B. (1987). Screening of patients admitted to a geriatric hospital with supposed organic dementia. Comprehensive Gerontology, $A 1,55-60$.

Nordensson, I., Adolfsson, R., Beckman, G., \& Winblad, B. (1980). Chromosomal abnormality in dementia of Alzheimer's type. Lancet, $i, 481-482$.

U.N. Department of International Economic and Social Affairs (1985). The world aging situation: Strategies and policies. E 85/14/5. New York: United Nations.

Bertil. Steen, M.D., Ph.D., Guest Editor

Department of Geriatric Medicine

Gothenburg University

Sweden 